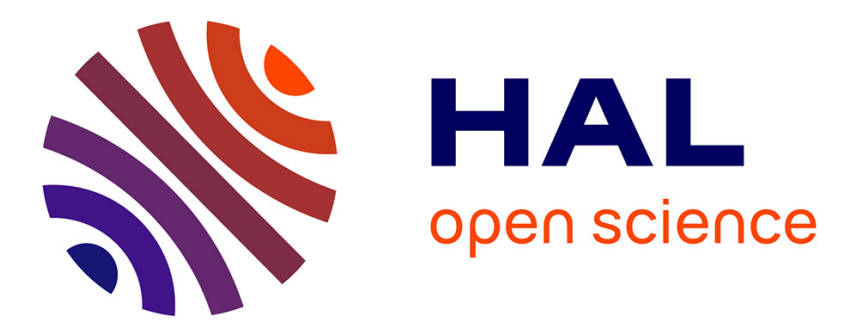

\title{
Culture savante, industrie culturelle et culture populaire dans la musique, la littérature et le cinéma brésiliens : un dialogue fécond \\ Rita Olivieri-Godet
}

\section{- To cite this version:}

Rita Olivieri-Godet. Culture savante, industrie culturelle et culture populaire dans la musique, la littérature et le cinéma brésiliens: un dialogue fécond. Amerika - Mémoires, identités, territoires, 2010, 10.4000/amerika.1086 . halshs-02872486

\section{HAL Id: halshs-02872486 \\ https://shs.hal.science/halshs-02872486}

Submitted on 17 Jun 2020

HAL is a multi-disciplinary open access archive for the deposit and dissemination of scientific research documents, whether they are published or not. The documents may come from teaching and research institutions in France or abroad, or from public or private research centers.
L'archive ouverte pluridisciplinaire HAL, est destinée au dépôt et à la diffusion de documents scientifiques de niveau recherche, publiés ou non, émanant des établissements d'enseignement et de recherche français ou étrangers, des laboratoires publics ou privés. 


\section{Amerika Amerika \\ Mémoires, identités, territoires \\ $2 \mid 2010$ \\ Frontières - La Mémoire et ses représentations \\ esthétiques en Amérique latine / 1}

\section{Culture savante, industrie culturelle et culture populaire dans la musique, la littérature et le cinéma brésiliens : un dialogue fécond}

Erudite culture, culture industry and popular culture in Brazilian music, literature and cinema : a fruitful dialog

\section{Rita Olivieri-Godet}

\section{(2) OpenEdition}

\section{Journals}

Édition électronique

URL : http://journals.openedition.org/amerika/1086

DOI : 10.4000/amerika.1086

ISBN : 978-2-8218-0200-1

ISSN : 2107-0806

Éditeur

LIRA-Université de Rennes 2

Ce document vous est offert par Université Rennes 2

Référence électronique

Rita Olivieri-Godet, « Culture savante, industrie culturelle et culture populaire dans la musique, la littérature et le cinéma brésiliens : un dialogue fécond », Amerika [En ligne], 2 | 2010, mis en ligne le 25 juillet 2010, consulté le 17 juin 2020. URL : http://journals.openedition.org/amerika/1086 ; DOI : https://doi.org/10.4000/amerika.1086

Ce document a été généré automatiquement le 17 juin 2020.

(c) Tous droits réservés 


\title{
Culture savante, industrie culturelle et culture populaire dans la musique, la littérature et le cinéma brésiliens : un dialogue fécond
}

\author{
Erudite culture, culture industry and popular culture in Brazilian music, \\ literature and cinema : a fruitful dialog
}

Rita Olivieri-Godet

1 L'intellectuel et critique littéraire brésilien Alfredo Bosi critique l'habitude de parler de la culture brésilienne «comme s'il existait une unité préalable qui agglutinerait toutes les manifestations matérielles et spirituelles du peuple brésilien. » Mais, ajoute-t-il, «il est clair qu'une telle unité ou uniformité semble n'exister en aucune société moderne, et, moins encore dans une société de classes $»^{1}$. Pour réfléchir sur les pratiques culturelles au Brésil (musique, littérature et cinéma), les connexions qu'elles établissent entre elles et leurs différentes sources de création, je prendrai comme point de départ le schéma analytique proposé par Bosi pour ensuite me consacrer à l'étude d'un cas précis, celui du Tropicalisme brésilien.

Si par le terme culture nous entendons un héritage de valeurs et d'objets partagé par un groupe humain d'une relative cohésion, nous pourrions parler d'une culture savante brésilienne, centralisée dans le système éducationnel (et principalement dans les universités), et d'une culture populaire, pour l'essentiel illettrée, qui correspond aux mores matériels et symboliques de l'homme de la campagne, du sertão ou de l'intérieur, et de l'homme pauvre des banlieues qui n'a pas encore été totalement assimilé par les structures symboliques de la cité moderne.»

A ces deux zones bien marquées,[...] nous pourrions en ajouter deux autres [...] La culture créatrice individualisée[...] la culture de masse, qui, par son intime imbrication avec les systèmes de production et de marché de biens de consommation, finit par être appelée par les interprètes de l'Ecole de Francfort, industrie culturelle, culture de consommation. $»^{2}$ 
2 Il faut surtout tenir compte de l'extrême complexité des imbrications qui se produisent entre la culture populaire et la culture de masse ou encore entre la culture savante et/ou créatrice des artistes et la culture populaire telles qu'elles sont présentées par Bosi et que je reprends ici. Ces imbrications culturelles font, à mon avis, la force et l'originalité de la production culturelle brésilienne moderne et contemporaine. Pour aller au-delà de considérations générales, j'ai choisi d'illustrer la fécondité de ces imbrications culturelles, par une analyse de la trajectoire du mouvement Tropicaliste ${ }^{3}$ qui puise sa force créatrice dans l'assimilation critique des éléments provenant de sources culturelles diverses.

\section{Qu'est-ce que le Tropicalisme?}

3 Le Tropicalisme, tendance esthétique qui naît à la fin des années 60 au Brésil, est tout d'abord un mouvement culturel qui surgit au sein de la musique populaire brésilienne et qui atteint par conséquent un public extrêmement large. Dans la culture brésilienne, c'est le seul mouvement artistique qui, ayant fait le choix d'allier une réflexion sur la réalité du pays à la sophistication constructive du langage, ait en même temps réussi à avoir un énorme succès populaire. Largement diffusée par les médias, l'expression musicale du Tropicalisme ne leur fera pas pour autant de concessions.

4 Le Tropicalisme s'inscrit dans la lignée des avant-gardes expérimentales brésiliennes qui l'ont précédé. Tout en gardant des points communs avec le Modernisme et la Poésie Concrète et des affinités avec le Cinéma Nouveau, le mouvement tropicaliste présente évidemment des caractéristiques très particulières que ce travail a l'intention de préciser.

5 Selon le compositeur et chanteur brésilien, Caetano Veloso, «Le mot clé pour comprendre le Tropicalisme est syncrétisme », mais il ajoute aussitôt que " tout le monde sait qu'il s'agit d'un mot dangereux » ${ }^{4}$.Pour ce chef de file du Tropicalisme, le syncrétisme concerne un certain regard ou un point de vue sur la culture qui provoque l'éveil de manifestations culturelles antagoniques, au lieu de promouvoir « une fusion homogène et moyennement acceptable » des données culturelles. Le point de départ du Tropicalisme est donc une perspective qui aura tendance à englober un ensemble de composantes culturelles antagoniques, en mettant côte à côte les éléments les plus hétéroclites, du kitsch au raffiné, de l'archaïque à l'industriel, du provincial à l'universel. On peut donc parler d'un regard panoramique qui se pose sur les choses, soit simplement pour les contempler, soit pour les critiquer, soit encore pour les exalter. Dans tous les cas, un regard qui ne refuse pas de voir ce qui existe et d'exposer, voire même de surexposer,les données du réel. Cela peut expliquer, en partie, l'importance des images visuelles dans les paroles des chansons tropicalistes ou le caractère théâtral des présentations en concert de ses artistes.

6 L'histoire du Tropicalisme est liée à la série de festivals de musique qui a regroupé la jeunesse universitaire de la deuxième moitié des années 60 autour de ses idoles. L'explosion tropicaliste a lieu lors du $3^{\text {ème }}$ Festival de Musique Populaire de la chaîne télévisée TV Record à São Paulo, en 1967, au cours duquel Caetano Veloso a présenté la chanson Alegria, Alegria, d'abord sous les huées d'une jeunesse qui ne supportait pas les guitares électriques, mais qui peu à peu finira par être sensible à ce que la chanson apportait de nouveau et de révolutionnaire. Caetano Veloso était accompagné par les Beat Boys, un groupe de rock brésilien et sa chanson a été classée en $4^{\text {ème }}$ position. Dans ce même festival, Gilberto Gil accompagné d'un autre groupe de rock national, Os Mutantes, a 
présenté la chanson Domingo no Parque, classée en deuxième position, dont l'arrangement de Rogério Duprat mélangeait berimbau, guitares électriques et orchestre.

7 L'origine du nom qui a été donné au mouvement vient du titre d'une chanson de Caetano Veloso, Tropicália. Ce nom lui a été suggéré par le photographe et producteur de cinéma Luís Carlos Barreto qui voyait dans les paroles de cette chanson des affinités avec l'œuvre $\mathrm{du}$ plasticien d'avant-garde Hélio Oiticica ${ }^{5}$. Caetano Veloso, qui avait été très impressionné par le film de Glauber Rocha, Terra em transe $(1967)^{6}$, venait d'écrire cette chanson, quand il est allé voir le montage de José Celso Martinez pour la pièce $O$ Rei da Vela de Oswald de Andrade. Il a alors compris que plusieurs artistes, dans les différents domaines de la création artistique, partageaient les mêmes préoccupations esthétiques avec les « tropicalistes » de la musique.

8 Après l'édition des disques solo de Caetano et de Gil, c'est en 1968 qu'est sorti le disquemanifeste Tropicália ou Panis et circensis (sic), réunissant Caetano Veloso, Gilberto Gil, Os Mutantes, Tom Zé, Gal Costa et Nara Leão, ainsi que les poètes José Carlos Capinan et Torquato Neto qui avec Caetano, Gil et Tom Zé ont écrit les paroles de quelques chansons. Le chef d'orchestre Rogério Duprat était le responsable des arrangements. Outre les compositions du groupe - marquées par la nouveauté et la sophistication constructive du langage musical qui n'hésitait pas à mélanger toutes sortes de genres et de styles pour exposer les images kitsch, populaires ou modernes du Brésil - ce disque incorpore un hymne religieux très populaire à Bahia et une chanson mélodramatique, Coração Materno, qui était considérée par l'élite intellectuelle comme une sorte de symbole du mauvais goût. Rogério Duarte, qui avait déjà élaboré les pochettes des disques de Gil et Caetano et qui était aussi l'auteur de la belle affiche du film de Glauber Rocha, Deus e o Diabo na Terra do Sol, a conçu le projet graphique de la couverture de ce disque-manifeste. Innovation, provocation, parodie, le disque était une geléia geral ${ }^{7}$, un défi aux valeurs esthétiques et idéologiques de l'époque.

9 Mon but n'est pas de décrire ici l'histoire du Tropicalisme, mais de reprendre les principaux repères de sa courte et explosive trajectoire (1967/1968) pour mieux comprendre son projet esthétique et ses rapports avec le contexte culturel et politique de l'époque ${ }^{8}$. Ainsi, au Festival de la TV Record de 1968, Tom Zé, compositeur originaire de l'intérieur de l'Etat de Bahia, a remporté le premier prix avec la chanson São São Paulo meu amor. Tom Zé a étudié dans le Seminário de Música da Bahia, qui à l'époque réunissait un important groupe de musiciens de l'avant-garde expérimentale, une des sources musicales qui ont alimenté les tropicalistes de Bahia, les autres étant la bossa nova de João Gilberto et toute la tradition de musique populaire (nationale mais aussi internationale) du folklore à la Jovem Guarda, de la samba traditionnelle au rock des Beatles. Ce même festival a encore primé Caetano Veloso dont la chanson Divino maravilhoso a été classée en $3^{\text {ème }}$ position. Cette chanson a donné son nom à une série d'émissions télévisées de la chaîne TV Tupi, avec la participation du groupe tropicaliste et de ses invités. Elle témoigne de l'usage important et polémique que les tropicalistes ont fait des mass media, s'attirant des critiques aussi bien des conservateurs de droite, choqués par leur comportement et leur apparence extravagants, que des militants de gauche, qui leur reprochaient d'être trop médiatisés et de ne pas faire preuve d'engagement politique.

Les événements du $3^{\text {ème }}$ Festival International de la Chanson (TV Globo, 1968) illustrent le conflit entre la jeunesse militante de gauche, liée au parti communiste brésilien qui avait une pénétration importante dans les CPC - Centres Populaires Culturels -, et le groupe de baianos tropicalistes. La chanson Questão de ordem de Gil est éliminée. Lors de la 
présentation, par Caetano Veloso, de sa chanson É proibido proibir - titre repris d'un slogan de mai 68 «Il est interdit d'interdire » - un scandale se produit ${ }^{9}$. Dès qu'il monte sur la scène, les huées du public l'empêchent de chanter. Caetano commence alors un discours qui a été enregistré et que l'on présentera par la suite comme «ambiance de festival», où il proteste contre l'élimination de la chanson de Gil, qualifie le jury d'incompétent, et compare le public aux agresseurs de droite de la comédienne Cacilda Becker. Sous les huées du public, il lance un défi en hurlant ces mots: «C'est cette jeunesse qui veut prendre le pouvoir? Si vous deviez être en politique comme vous êtes en esthétique, nous sommes fichus. »

11 D'aucuns ont voulu nier la dimension politique du Tropicalisme. Cela s'explique par la tendance générale, dans les périodes historiques critiques, à exiger de l'art un engagement politique explicite. Je pense cependant que la dimension politique, voire même révolutionnaire, du Tropicalisme, se trouve dans le fait qu'il rejette une vision schématique du politique, en tissant des liens entre radicalité critique et réalisation esthétique. "Quand il s'agit de l'art, il est toujours dangereux d'oublier la perspective esthétique " écrit Caetano Veloso dans son livre Alegria, Alegria ${ }^{10}$. La déstructuration formelle pratiquée par le Tropicalisme est une pratique subversive, car en imposant un nouveau fonctionnement aux différents langages artistiques, elle fonde également un regard nouveau sur la réalité.

Néanmoins si la gauche se méfiait de l'engagement politique des tropicalistes, les militaires eux, n'ont pas eu de doutes. En décembre 1968, après le décret AI-5 (Ato Institucional $n^{\circ} 5$ ), et la dissolution du Congrès, la répression militaire se durcit. Gilberto Gil et Caetano Veloso sont arrêtés et ils restent en prison pendant deux mois. Après leur libération, ils prennent le chemin de l'exil. En juin 1969, ils donnent un dernier concert Barra 69 - au théâtre Castro Alves à Salvador, faisant ainsi leurs adieux avant de partir pour l'Angleterre ${ }^{11}$.

Dans le contexte explosif et rebelle des années 60 , le rôle révolutionnaire du Tropicalisme ne s'est pas restreint aux changements radicaux introduits dans le langage artistique. Il a également contribué à changer les mœurs et la mentalité des gens, ce qui a conduit quelques spécialistes du mouvement, en observant les changements de comportement de toute une génération, à le rapprocher des événements de " mai 68 » en France ${ }^{12}$. Dans un contexte répressif et moraliste, qui était celui de la dictature, le rire anarchique et débauché des tropicalistes, leur choix d'une esthétique de l'impact, leur mise en scène de la fête, de la jouissance, leur représentation tragi-comique de la réalité brésilienne, sont autant d'éléments qui construisent un chant libéré et libertaire dans une terre emprisonnée et bâillonnée.

\section{Tropicalisme et industrie culturelle}

Il y aurait toute une discussion à développer sur les possibilités de survie de l'art dans une société capitaliste avancée, selon que l'on se place dans la perspective de Théodore Adorno ou dans celle de Walter Benjamin. Tous deux considèrent que l'industrie culturelle programme l'exploitation des biens culturels, en adaptant ses produits à la consommation des masses, mais en tirent des conclusions différentes. Adorno considère que le développement technologique tend nécessairement à l'homogénéisation et, par conséquent, empêche la distinction entre l'œuvre d'art et le système social qui la contamine et la neutralise. Au contraire, Walter Benjamin n'attribue pas à l'industrie 
culturelle ce pouvoir absolu de neutralisation. Le progrès des techniques de reproduction de l'art fait disparaître son caractère élitiste. La disparition de l'aura de l'oeuvre d'art atteint des dimensions esthétiques et sociales et introduit des modifications dans la perception esthétique. L'art perd son caractère d'unicité et se manifeste de façon multiple et fragmentaire. Selon Walter Benjamin, cette vision fragmentaire propre à l'allégorie moderne exerce une fonction de subversion de l'idéologie dominante.

Si l'on réflechit aux paroles des chansons tropicalistes comme Tropicalia, Superbacana, Alegria, Alegria, Geléia geral, entre autres, on y retrouve cette vision fragmentaire moderne à laquelle Benjamin fait allusion. La présence de signes représentatifs de la société de consommation contraste avec des éléments du contexte socio-culturel brésilien et latinoaméricain. Le collage superpose des éléments disparates ( le bon et le mauvais goût, l'urbain et le rural, l'artisanal et l'industriel) dans un langage discontinu, chaotique. Images et discours s'entrecroisent, en exacerbant ce qu'il y a de fragmentaire dans l'expérience urbaine. Sophistication formelle, construction cubiste, discours parodique contrastent avec la simplicité, voire même la banalité des images du quotidien évoquées par les compositions tropicalistes. Sur les pas du Modernisme, le Tropicalisme rapproche une attitude avant-gardiste expérimentale des formes populaires de l'expression culturelle, en englobant dans son champ d'intérêt, outre le primitivisme, la culture de masse. A propos de la chanson Tropicália Caetano écrira: « [...] j'ai imaginé de mettre côte à côte des images, des idées et des entités révélatrices de la tragi-comédie Brésil, des images de l'aventure à la fois frustrante et reluisante d'être Brésilien $»^{13}$.

En syntonie avec le pop'art, les tropicalistes intègrent le répertoire iconique de la culture urbaine de masse. La rupture esthétique, s'appuyant sur un projet radical d'innovation du langage artistique, souligne le désaccord idéologique avec les valeurs conservatrices et répressives de la société brésilienne et contribue ainsi à corroder l'idéologie officielle. Leur attitude esthétique, intentionnellement provocatrice, les conduit à un usage hétéroclite des éléments kitsch de la culture brésilienne. Dans leurs productions, l'assemblage des images multiples superpose les aspects les plus divers de la réalité, en exposant à la fois le quotidien d'une société de consommation, l'inégalité sociale et le sous-développement du pays, mais aussi la joie de vivre et le rire subversif de son peuple. La construction allégorique s'appuie sur les images morcelées qui entrecroisent les clichés du monde moderne avec les aspects archaïques de la culture. Elle empêche ainsi la projection d'une image unifiée de la nation. Ce refus d'un sens unique, dans un contexte où le nationalisme des militaires essayait de faire passer l'image d'un pays stable et puissant, acquiert une signification politique importante. À sa place, la simultanéité d'images contradictoires et les énumérations chaotiques mettent en scène une représentation en ruines, dont les débris nous invitent à regarder dans tous les sens.

La tendance cosmopolite et urbaine du Tropicalisme se manifeste par l'intégration du pop'art. Les tropicalistes expriment un refus de la culture traditionnelle européenne qui, pour eux, se confond avec une conception élitiste et académique de l'art. Il s'agit d'une attitude semblable à celle des modernistes qui, eux aussi, réagissaient contre la fascination que la culture européenne traditionnelle exerçait sur l'ensemble de la société brésilienne. Tandis que le penchant cosmopolite de l'avant-garde moderniste la met en rapport avec l'avant-garde européenne, le Tropicalisme mettra au centre de ses préoccupations la question de l'industrie culturelle, se tournant vers l'avant-garde américaine. Cependant, si le projet iconoclaste des tropicalistes les rapproche davantage de l'avant-garde américaine, il n'ignore pas pour autant l'expérience avant-gardiste de la 
Nouvelle Vague du cinéma français, en particulier les films de Jean-Luc Godard. D'autre part, les échos des mouvements de contestation en Europe, particulièrement celui de mai 68 en France, retentissent au Brésil. On les retrouve sous la forme d'un comportement provocateur et anarchique que les tropicalistes poussent à l'extrême.

La production culturelle de la deuxième moitié des années 60 a du faire face au contexte répressif de la dictature et à l'hégémonie des mass media. Face à cette hégémonie, il y avait deux tactiques de résistance possibles: une première tendance a essayé de créer ses propres moyens alternatifs de divulgation de sa production culturelle; une deuxième attitude, adoptée par les tropicalistes, a consisté à se servir des moyens de communication sans renoncer à une vision critique.

tropicalistes non seulement adoptent une stratégie « d' empoisonnement des médias ", comme le souligne le poète Álvaro de Sá ${ }^{14}$, mais ils font encore le choix d'incorporer la thématique et la technique de l'industrie culturelle. Ils se servent des contradictions de la société de consommation, sans néanmoins les critiquer de façon explicite. Cette dimension dialectique du Tropicalisme n'a pas toujours été comprise, surtout dans le contexte tendu de la dictature. Les partisans de l'art engagé, qui à l'époque érigeaient la « canção de protesto » en modèle, n'ont eu de cesse d'accuser les tropicalistes de jouer le jeu de l'idéologie dominante.

20 Selon Caetano Veloso, les protagonistes du Tropicalisme cherchaient une autre réponse aux problèmes posés par la réalité brésilienne que celles proposées par la gauche traditionnelle. Pour dévoiler les mystères du Brésil, ses traits complexes et paradoxaux, ils se sont tournés aussi bien vers les formes populaires traditionnelles que vers celles de la culture de masse et se sont appropriés les techniques expérimentales de l'avant-garde internationale.

\section{Tropicalisme : un dialogue intersémiotique}

21 Le caractère hybride du mouvement tropicaliste se manifeste à travers les sources auxquelles il va puiser pour construire son langage novateur : sources musicales, comme nous l'avons vu, mais aussi littéraires (le Modernisme, la Poésie Concrète), cinématographiques (Jean Luc Godard, Glauber Rocha), théatrales (O Rei da Vela, montage de José Carlos Martinez) ou plastiques (le pop'art, les affinités avec l'œuvre d'Hélio Oiticica). Le groupe de musiciens qui est à l'origine du Tropicalisme a toujours établi un dialogue intense avec d'autres langages artistiques, guidé par le penchant expérimental du projet. Ainsi, s'il se laisse traverser par certaines réalisations des avant-gardes artistiques, il va à son tour contribuer à façonner de nouvelles expériences.

De cet échange productif résulte le fait que le Tropicalisme constitue aussi un mouvement collectif capable d'ébranler les différents langages artistiques, celui de la musique (domaine dans lequel il trouve son expression la plus achevée), mais aussi ceux des arts plastiques, du théâtre, du cinéma et de la littérature.

Contrairement aux avant-gardes précédentes, la littérature y occupe une place secondaire. Quelques poètes, proches du mouvement de la poésie alternative ou marginale, ont écrit des paroles de chansons ${ }^{15}$. En dehors de ces travaux les textes tropicalistes sont rares. PanAmérica (1967) ${ }^{16}$ et Nações Unidas (1968) de l'écrivain paulista José Agrippino de Paula ${ }^{17}$, ou Deus da chuva e da morte (1962) de Jorge Mautner ${ }^{18}$ sont des exceptions qui ne font que confirmer la règle. 

gardes poétiques de l'époque. C'est le cas par exemple du Poema-Processo (1967-1972) qui lui aussi préconise une rupture avec une poésie discursive, rupture que ses adeptes poussent jusqu'à effacer le signe verbal au profit d'une contamination par d'autres systèmes sémiologiques, en utilisant toutes sortes de supports médiatiques. Ce mouvement prône l'insertion de la poésie dans la réalité de la société de consommation et ses poètes n'hésitent pas à avoir recours à des stratégies agressives et iconoclastes, en transformant la poésie en un grand spectacle, en un vrai happening (Waldomiro Dias Pino, Alvaro de Sá). Et il y a évidemment les concrétistes qui, eux aussi, s'interrogent sur le statut du signe verbal, refusent le langage discursif et s'ouvrent vers d'autres systèmes sémiologiques. Parmi les concrétistes ${ }^{19}$, Augusto de Campos sera le premier à fournir au Tropicalisme des éléments pour son fondement théorique.

C'est à partir des essais d'Augusto de Campos $^{20}$, que le trajet Modernisme - Concrétisme Tropicalisme est mis en évidence, par le biais de l'œuvre d'Oswald de Andrade que Campos proclame comme mentor. Dans ses essais, Augusto de Campos met en évidence le caractère novateur du Tropicalisme, tout en soulignant l'aspect hybride du mouvement qui n'hésite pas à rapprocher poésie érudite et poésie populaire. Selon Campos, ce qu'il y avait de nouveau dans la poésie brésilienne avait migré des pages des livres vers la chanson populaire.

L'intérêt qu'Augusto de Campos portait au pop'art et à la théorie de la communication à partir de l'année 64, époque où il s'est consacré à la composition des poèmes 'popcretos' (exposés à la Gallerie Atrium), a probablement favorisé l'accueil chaleureux qu'il a fait au Tropicalisme. Il fut le premier à se référer au disque solo de Caetano Veloso, Tropicália (1967) comme "oswaldien ", " anthropophage », « démystificateur ». Le caractère anthropophage est mis en évidence pour répondre à ceux qui voyaient dans le processus d'absorption des techniques nouvelles de l'avant-garde internationale, un signe de dépendance culturelle.

Du Modernisme au Tropicalisme il y a tout un parcours anthropophage qui permet de les rapprocher. Tous deux sont marqués par l'ambition de réaliser une réinterprétation de la culture brésilienne. Ils ont en commun une façon de se tourner vers la réalité du pays, en la regardant d'un œil qui revêt une dimension anthropologique. Leur désir de moderniser la culture brésilienne, c'est-à-dire de la mettre en accord avec leur temps, ne s'arrête pas aux innovations formelles, indispensables mais insuffisantes pour faire aboutir des projets de cette ampleur. Leur esprit iconoclaste a renouvelé de façon substantielle la culture et a réussi à ébranler la mentalité conformiste brésilienne. Modernisme et Tropicalisme partagent le même élan de rupture radicale, tant avec les modèles traditionnels des langages artistiques, qu'avec les structures idéologiques dominantes. Chacun à sa façon, ils réalisent un effort de synthèse entre la spécificité brésilienne et la culture moderne occidentale. Ce sont là autant d'éléments qui nous incitent à rapprocher ces deux mouvements pour mieux évaluer la contribution moderniste à la culture brésilienne contemporaine.

L'aventure tropicaliste représente, sur les pas du Modernisme, un effort dans le sens de renouveler l'intelligence nationale. Cette mise en question de la production culturelle brésilienne se fait simultanément aux niveaux esthétique, thématique et idéologique. Les deux mouvements ont une conception culturelle syncrétique, allant à la rencontre des différentes sources qui nourrissent la culture brésilienne: les richesses de la langue et de l'imaginaire populaire, la culture savante ancrée dans ses racines européennes et, dans le 
cas du Tropicalisme, les éléments de l'industrie culturelle. Ils dialoguent avec les avantgardes internationales et alimentent le projet ambitieux d'exporter leur production. Ils se tournent vers le quotidien bourgeois des villes modernes qu'ils n'hésitent pas à confronter à des aspects archaïques de la réalité brésilienne. Pour sa part, le Tropicalisme va aussi exposer les blessures d'un pays sous-développé et économiquement dépendant. Le Modernisme et le Tropicalisme posent la question de l'identité nationale, et incorporent les représentations stéréotypées du pays pour les démythifier par la construction d'un discours parodique. Enfin, les deux mouvements soulèvent la problématique de l'insertion du Brésil dans un espace culturel latino-américain. Cette tendance que le Modernisme avait à peine ébauchée s'est considérablement développée avec les tropicalistes qui, sur les traces du Cinéma Nouveau de Glauber Rocha, revendiquent une parole originaire « $\mathrm{du}$ fin fond obscur du cœur solaire de l'hémisphère sud $»^{21}$.

\section{Tropicalisme et Cinéma Nouveau} la réalité brésilienne, nous fait découvrir plusieurs points communs avec le nationalisme esthétique de Mário de Andrade. Il éprouve le même besoin de connaître de près les régions intérieures du pays les plus éloignées de la culture urbaine. En 1958, il réalise son premier voyage dans le Nord-Est et dans le sertão de Bahia. Il en revient impressionné par la région de Monte Santo, où il filmera plus tard Deus e o Diabo na Terra do Sol. Il rencontre alors Ascenso Ferreira, poète représentatif du mouvement régionaliste du Nord-Est, qui par ailleurs entretient des liens d'amitié avec Mário de Andrade. Pour Glauber, comme pour de nombreux artistes du Nord-Est du Brésil, aux préoccupations formelles de la phase héroïque du Modernisme (1922-1930) est venue se superposer l'influence des thématiques régionales. Ces deux facettes modernistes ont permis à Glauber de développer son propre langage artistique. La phase régionaliste de l'expression moderniste, impulsée par Gilberto Freyre, caractéristique de la production artistique du Nord-Est pendant les années 30, a été un facteur déterminant dans les premiers films de Glauber Rocha. Les romans Pedra Bonita et Cangaceiros de l'écrivain José Lins do Rego, un des principaux représentants du régionalisme du Nord-Est, constituent une référence majeure pour Glauber qui, dans ses écrits de jeunesse, fait la présentation de l'œuvre romanesque de cet auteur. Dans son analyse de Pedra Bonita, on retrouve les éléments que le futur réalisateur de Deus e o Diabo na Terra do Sol reprendra dans ce film:

o Nordeste aparece dominado por quatro elementos vigorosos: o coronel, o tenente das volantes, o santo e o cangaceiro. São quatro poderes de opressão e desses, os únicos que amam o povo, embora o torturem, é o cangaceiro, vingador natural, é o santo, redentor dos pecados e misérias. ${ }^{23}$

Malgré la beauté et la force allégorique de Deus e o Diabo..., ce film projette l'image du pays à partir d'une réalité particulière. Il n'est pas difficile de comprendre pourquoi les 
tropicalistes qui ont une vision panoramique et syncrétique du pays, englobant les composantes hétéroclites de la réalité urbaine, vont préférer proclamer Terra em transe comme l'oeuvre de référence du Cinéma Nouveau, bien que ce film ait, à l'époque, reçu du public un accueil mitigé. Selon le témoignage de Caetano Veloso, l'impact que le film Terra em transe (1967) de Glauber Rocha a exercé sur lui, est à l'origine du mouvement tropicaliste ${ }^{24}$. Le regard anthropologique et désabusé que le film pose sur la réalité brésilienne, l'excès de ses images baroques, la critique des structures oppressives qu'il dénonce même chez les groupes qui se positionnaient contre l'oppression, à savoir, la gauche stalinienne, le langage fragmenté et apparemment illogique, l'inclusion de la société brésilienne dans un contexte du Tiers Monde, tout ces éléments vont à la rencontre des penchants esthétiques et idéologiques du Tropicalisme. Ce film peut être considéré comme un précurseur de la tendance esthétique tropicaliste.

La critique du dogmatisme et du messianisme de gauche, de sa conception d'un art populaire révolutionnaire qui érigeait comme but l'endoctrinement idéologique au détriment de l'expérimentation et de la qualité esthétique, rapproche le Cinéma Nouveau de Glauber Rocha du Tropicalisme de Caetano Veloso. Les deux projets vont se heurter contre les théories esthétiques de la gauche communiste traditionnelle, caractéristiques des artistes et intellectuels des CPC - Centro Popular de Cultura. La création artistique, aussi bien pour Caetano que pour Glauber, ne doit pas réduire la dimension esthétique à un rôle de support idéologique :

Apesar de fazer cinema voltado para a realidade social, nunca admiti nenhuma forma de demagogia estética em face de uma arte política ; porque o que acontece é que existem intelectuais, escritores, artistas e cineastas que justificam uma péssima qualidade da obra artística em nome da intenção política progressista. Isso é traição que não admito, porque acredito que o fenômeno político, o fenômeno social, só ganham sua importância artística quando expressos através de uma obra de arte que seja colocada numa perspectiva estética. Ou seja a bela frase de Brecht que diz: " para novas idéias, novas formas $" .^{25}$

33 La fin de cette citation met en évidence le penchant expérimental propre aux avantgardes et très cher aux projets du Cinéma Nouveau et du Tropicalisme. Même si la recherche d'un langage nouveau parcourt des chemins différents (le Cinéma Nouveau essayant d'extraire de la précarité la force de son originalité, le Tropicalisme s'ouvrant à toutes sortes d'innovations techno-industrielles) leur but commun est de ne pas négliger l'aventure expérimentale.

34 Un autre point qu'il me paraît important de souligner et qui me permet de rapprocher Tropicalisme et Cinéma Nouveau est la préoccupation de tisser les liens entre la réalité brésilienne et le contexte de l'Amérique Latine :

A noção de América Latina supera a noção de nacionalismos. Existe um problema comum : a miséria. Existe um objetivo comum : a libertação econômica, política e cultural para fazer um cinema latino. Um cinema empenhado, didático, épico, revolucionário. Um cinema sem fronteiras, de língua e problemas comuns. ${ }^{26}$

Ce souci de représenter le Brésil en tant que pays latino-américain, en soulignant son appartenance au contexte du Tiers Monde se traduit au sein même du langage, par l'adoption d'une poétique de la violence, privilégiant les images d'une exubérance agressive, le morcellement du langage, le délire des formes absurdes apparemment illogiques et chaotiques. Au niveau thématique, cette préoccupation s'affirme par la mise en scène de la misère, de la violence urbaine, de la guérilla. On retrouve ces caractéristiques dans des chansons tropicalistes telles que Soy loco por ti, América (1967), 
« un poème né du corps d'un guérillero mort en Bolivie et de son exposition à la une des journaux $»^{27}$, composé par José Carlos Capinan, Torquato Neto et Gilberto Gil, mélangeant l'espagnol et le portugais. C'est également le cas pour les films de Glauber tels que : Terra em transe (1967), «une allégorie sur les partis communistes en Amérique Latine ${ }^{28}$; Cabezas Cortadas (1970) «il s'agit d'un film contre les dictatures, c'est l'enterrement des ditactures $»^{29}$ ou A idade da Terra (1980) - qui, dans sa première version de 1969, s'appelait América Nuestra - «il s'agit d'un film qui parle des tentatives du Tiers Monde »

Peut-on parler d'un cinéma tropicaliste? Je préfère plutôt me référer aux interférences réciproques entre le Tropicalisme et quelques films du Cinéma Nouveau réalisés après Terra em transe. Le seul projet concret qui a eu le mérite de regrouper tropicalistes et cinemanovistas, (selon Caetano, un projet très influencé par Terra em transe), fut la réalisation du film Brasil, ano 2000 (1968), « une allégorie musicale conçue par Walter Lima Jr., sur la distanciation entre le Brésil et les temps modernes $»^{31}$. Dans ce film, les chansons sont de Gil, Capinan et Caetano ; la direction musicale est de Rogério Duprat (l'arrangeur du disque-manifeste du Tropicalisme), la production est de Glauber Rocha, et la mise en scène de Walter Lima Jr. Contrairement aux productions tropicalistes de l'époque, le film fut un échec commercial.

Il est possible de voir dans la production du Cinéma Nouveau à partir de 1968 (dans les films de Glauber, mais aussi dans ceux d'autres réalisateurs comme Nelson Pereira dos Santos, Cacá Diegues, Joaquim Pedro de Andrade), des allégories et des éléments qui ont des affinités avec l'esthétique tropicaliste. Mais, sans doute, à mon sens, Macunaíma (1969) de Joaquim Pedro de Andrade est le film qui se rapproche le plus de l'esthétique tropicaliste. Ce film se trouve à la croisée de trois mouvements de l'avant-garde brésilienne : le Modernisme, le Cinéma Nouveau et le Tropicalisme. Dans ce film, le parti pris pour un art excessif donne lieu à des images extravagantes accentuées par les couleurs, les décors et les costumes, aux aspects allégoriques, parodiques et carnavalesques de la mise en scène, à l'assemblage d'éléments disparates. Si l'on prête attention à la musique du film, on constate qu'elle présente les tendances caractéristiques du mouvement tropicaliste. Elle joue sur l'imprévisible et la dissonance, elle met côte à côte, entre autres, Villa Lobos, compositeur classique, le chanteur Roberto Carlos, représentant le iê, iê, îe (version brésilienne du rock) et Luís Gonzaga, compositeur et chanteur des rythmes populaires et traditionnels du Nord-Est. On retrouve enfin l'image paradoxale et tragi-comique d'un Brésil archaïque et moderne.

Il y a toujours eu des interactions entre ces deux mouvements de l'avant-garde artistique brésilienne, et quelques projets ont été partagés par leurs chefs de file, dont certains n'ont pas pu être réalisés : celui de Glauber, par exemple, qui rêvait de filmer $O$ Guarani à partir de l'opéra de Carlos Gomes, avec Caetano dans le rôle principal. Il semblerait que Caetano ait trouvé ce projet trop nationaliste. Par ailleurs, en faisant le bilan du Cinéma Nouveau, dans Revolução do Cinema Novo, Glauber cite le nom du compositeur parmi les premiers artistes qui en faisaient partie ou qui appuyaient ce mouvement. Dans son livre Verdade tropical, Caetano insiste sur le caractère démolisseur du cinéaste, en le rapprochant de la personnalité d'Oswald de Andrade. Il l'appelle Glauber-Oswald, synthétisant dans cette trouvaille métaphorique, l'héritage du Modernisme et du Cinéma Nouveau, à partir d'un point de vue tropicaliste qui rapproche le national et le cosmopolitisme.

39 Un autre point de convergence entre le Cinéma Nouveau et le Tropicalisme est la « déglutition anthropophage » de l'œuvre de Jean-Luc Godard. Ce réalisateur a marqué de 
son empreinte la production artistique de Caetano Veloso et de Glauber Rocha. Dans son film Le vent d'Est (1969), Glauber, qui a une petite participation, répond à la question qui lui est posée "Où va le cinéma du Tiers Monde? ", en chantant le refrain de la chanson Divino e maravilhoso composée par Caetano et Gil : «É preciso estar atento e forte / Não temos tempo de temer a morte ».

Ces interactions et convergences entre les deux mouvements disent beaucoup du projet esthétique et idéologique de toute une génération qui rêvait de liberté et qui a dû faire face à la répression de la dictature militaire. Le Tropicalisme et le Cinéma Nouveau ont eu l'audace de créer un nouveau langage et d'inaugurer un regard original sur la réalité brésilienne ; ils ont osé nous proposer, selon les paroles de la chanson Cinema Novo du CD Tropicália II, «visões das coisas grandes e pequenas / que nos formaram e estão a nos formar $\|^{32}$.

41 À plusieurs reprises, Caetano Veloso exprime, dans Verdade Tropical, son attachement profond au Cinéma Nouveau. On comprend mieux cet attachement, en étant conscient du contexte culturel de Bahia pendant la période qui comprend la fin des années 50 et le début des années 60. D'une certaine façon, on peut dire que ce n'est qu'à la fin des années 50 que le Modernisme a porté ses fruits dans la production artistique de Bahia ${ }^{33}$. La génération qui se réunit autour de la revue $\mathrm{Mapa}^{34}$ reprend le chemin que les modernistes paulistas des années 20 s'étaient frayé. À ce moment-là - à l'exception de quelques voix (les poètes Eurico Alves ${ }^{35}$ et Godofredo Filho) - ce mouvement d'avant-garde n'avait pas réussi à pénétrer les milieux conservateurs des intellectuels de l'Etat de Bahia. Ce n'est qu'à partir de la fin des années 50, que Salvador de Bahia a vécu une vraie effervescence culturelle, avec l'apparition de noms qui ont définitivement marqué la culture brésilienne dans les différents domaines de l'art: João Gilberto, Glauber Rocha, Caetano Veloso, Gilberto Gil, João Ubaldo Ribeiro, pour ne citer que ceux qui jouissent d'une projection nationale et internationale remarquable. Période qui constitue pour l'histoire intellectuelle de Bahia une sorte de renaissance moderniste. ${ }^{36}$

C'est donc dans ce contexte de riches discussions sur la production artistique dans ses différents domaines que le groupe de jeunes compositeurs, chanteurs et poètes de Bahia, qui était à l'origine de l'expression musicale du Tropicalisme, a été formé. Sans vouloir être déterministe, on peut considérer que ce contexte a stimulé la création d'un mouvement ouvert à l'interaction avec les autres langages et organisé autour d'un projet, d'une production représentative et d'une œuvre-manifeste. Cela a permis d'établir un vrai dialogue intersémiotique, en créant des œuvres contaminées par d'autres systèmes sémiologiques, mais qui auront aussi le mérite d'être suffisamment innovatrices pour les imprégner fortement de ses éléments. Ainsi, l'importance du Tropicalisme dépasse largement la courte période de deux ans de cette fin des années 60 , phase héroïque de son existence en tant que mouvement d'avant-garde. Elle persiste, au-delà de ces limites chronologiques, dans une tendance esthétique qui est toujours présente dans la culture brésilienne et qui ne cesse de nous surprendre par sa créativité, son humour et son exubérante irrévérence. 


\section{BIBLIOGRAPHIE}

BOSI, Alfredo, La culture brésilienne : une dialectique de la colonisation, Paris : L'Harmattan, 2000.

CAMPOS, Augusto de, Balanço da bossa e outras bossas, São Paulo : Perspectiva, 1974.

GODET, Rita Olivieri, «Le Tropicalisme brésilien et ses rapports avec le Modernisme et le Cinéma Nouveau ", Quadrant : revue du Centre de Recherche en Littérature de Langue Portugaise, Montpellier : Université Paul-Valéry, 2001, p. 133-156.

GODET, Rita Olivieri, A poesia de Eurico Alves. Imagens da cidade e do sertão, Salvador, EGBA / Secretaria da Cultura, Coleção Selo Editorial Letras da Bahia, 1999.

GODET, Rita Olivieri, « Le Modernisme à Bahia : tradition et avant-garde dans l'oeuvre d'Eurico Alves Boaventura ». In : GODET, Rita Olivieri (sous la direction de) Le Modernisme brésilien, Paris : Université Paris 8, Série Travaux et Documents n 10, 2000, p. 135-167.

GODET, Rita Olivieri, « Macounaïma : le plaisir ludique du texte ». In : ANDRADE, Mário. Macounaïma, le héros sans aucun caractère, Edition critique française / Pierre Rivas (coord.). Paris Stock-Unesco, 1996, p. 263-288.

GOMES, José Carlos Teixeira, Glauber Rocha, esse vulcão, Rio de Janeiro : Nova Fronteira, 1997. HOISEL, Evelina, Supercaos : os estilhaços da cultura em " PanAmérica e « Nações Unidas », Rio de Janeiro: Civilização Brasileira; Salvador: Fundação Cultural do Estado da Bahia, 1980.

LYRA, Pedro, Sincretismo. A poesia da geração 60, Rio de Janeiro : Topbooks, 1995.

REVISTA DA BAHIA, n 26, Tropicália 30 anos, mai 1998, Salvador: Fundação Cultural do Estado da Bahia /Empresa Gráfica da Bahia.

MACIEL, Luiz Carlos, Geração em transe. Memórias do tempo do tropicalismo, Rio de Janeiro : Nova Fronteira, 1996.

RISERIO, Antônio, Avant-garde na Bahia, São Paulo : Instituto Lina Bo e P. M. Bardi, 1995.

ROCHA, Glauber, « Romance de José Lins do Rego », Mapa, n² 2, Salvador: ABES, 1957.

ROCHA, Glauber, Revolução do Cinema Novo, Rio de Janeiro: Alhambra / Embrafilme, 1981.

VASCONCELLOS, Gilberto, Música popular: de olho na fresta, Rio de Janeiro : Edições do Grall, 1977.

VELOSO, Caetano, Verdade Tropical, São Paulo : Companhia das Letras, 1997.

VELOSO, Caetano, Alegria, Alegria, Rio de Janeiro : Pedra que Ronca, 1969.

\section{NOTES}

1. Alfredo Bosi, La culture brésilienne : une dialectique de la colonisation, L'Harmattan, 2000, p 363.

2. Alfredo Bosi, op. cit. p. 364 .

3. Ce texte est une version remaniée de l'article "Le Tropicalisme brésilien et ses rapports avec le Modernisme et le Cinéma Nouveau", Quadrant : revue du Centre de Recherche en Littérature de Langue Portugaise, Montpellier : Université Paul-Valéry, 2001, p. 133-156. 
4. Caetano Veloso, Verdade Tropical. São Paulo, Companhia das Letras, 1997, p. 292.

5. Sur les détails de l'origine du nom «Tropicalisme» et ses rapports avec l'œuvre de Hélio Oiticica voir Caetano Veloso, op. cit. p. 188.

6. «Num encontro na casa do arquiteto e letrista Marcos Vasconcellos, no Rio, ouvimos todo o álbum num gravador de rolo (o disco estava mixado, mas ainda não tinha sido prensado) e Glauber, coerentemente exultou com «Tropicália ». Ele claramente reconhecia as identificações com Terra em transe. " Caetano Veloso, Verdade Tropical, São Paulo, Companhia das Letras, 1997, p. 189.

7. L'expression est rentrée dans le langage courant de l'époque, pour signifier un assemblage d'éléments hétéroclites, l'idée de chaos, de désordre. Elle reprend le titre de la chanson Geléia Geral, composée par Torquato Neto et Gilberto Gil, qui faisait partie du répertoire de ce disque. Cette chanson est devenue (avec Tropicália) la principale référence musicale du Tropicalisme.

8. Pour des éléments précis sur l'histoire de l'aventure tropicaliste, je vous renvoie au numéro spécial de la revue Revista da Bahia, n²6, Tropicália 30 anos, mai 1998, Salvador, Fundação Cultural do Estado da Bahia /Empresa Gráfica da Bahia, référence bibliographique incontournable pour tous ceux qui s'intéressent à ce mouvement.

9. Dans Verdade Tropical, Caetano Veloso affirme avoir prévu ce happening : ses habits, ses mouvements, son discours, tout en lui était de la provocation. Il entendait ainsi choquer la gauche nationaliste, blesser sa vision moraliste et dogmatique d'un art engagé. Voir à ce sujet, Caetano Veloso, op. cit., p. 300-301.

10. Caetano Veloso, Alegria, Alegria, Rio de Janeiro, Pedra que Ronca, 1969.

11. Pour tous ceux qui n'ont pas eu la chance de voir ce dernier concert, ça vaut la peine de reproduire le commentaire de José Carlos Teixeira : «Os dois ainda conseguem obter permissão das autoridades militares para fazer um show no Teatro Castro Alves, em Salvador, alegando que precisavam conseguir dinheiro para as passagens e para manter suas famílias durante os primeiros meses de exílio, já que estavam há seis meses sem trabalhar. Os baianos lotam o Teatro Castro Alves para despedir-se de Caetano e Gil. No palco, eles fazem um balanço do Tropicalismo, com um variado repertório, verdadeiro mosaico das tendências abraçadas pelo movimento: bossa-nova, fado, tango, samba, rumba, toada sertaneja, frevo, baião, rock, o Hino do Senhor do Bonfim e até o Hino do Esporte Clube Bahia. O Tropicalismo que de brincadeira eles haviam sepultado no final do ano anterior, num quadro do programa Divino Maravilhoso, na TV Record, estava acabando ali, naquele momento, com suas duas principais estrelas cantando junto com a platéia um recado para o povo brasileiro: Alô, Rio de Janeiro, aquele abraço. " José Carlos Teixeira, « Malinagens de Exumacunaíma », Revista da Bahia, n 26, Tropicália 30 anos, mai 1998, Salvador, Fundação Cultural do Estado da Bahia /Empresa Gráfica da Bahia, p. 39.

12. «Mas o Tropicalismo pós-concretista, ostenta as cores incendiárias que a precipitação historicista confinara ao início do século. Por essa via, o movimento vai ultrapassar o limite estético, adquirindo significado comportamental. E mais : assumirá um ar de «maio 68 » das artes. Sous le pavé, la plage.» Antônio Risério, «Tropicalismo», Revista da Bahia. n 26, Tropicália 30 anos, maio 1999, p. 11.

13. Caetano Veloso, op. cit., p. 184.

14. Cité par Pedro Lyra dans son livre Sincretismo. A poesia da geração 60 , Rio de Janeiro, Topbooks, 1995, p. 121.

15. Torquato Neto, José Carlos Capinan, Wally Salomão.

16. Les paroles de Sampa, chanson composée par Caetano Veloso en hommage à São Paulo, reprennent le titre de cette œuvre de Agrippino de Paula: "panaméricas de Áfricas utópicas túmulo do samba mais possível novo quilombo de zumbi ».

17. Il faut préciser que si d'une part, l'écrivain José Agrippino de Paula n'a pas revendiqué de présenter ses travaux sous la bannière tropicaliste, d'autre part il est indéniable, comme le démontre Evelina Hoisel, dans son étude sur l'œuvre de l'auteur, que ses textes incorporent les 
principes esthétiques de ce mouvement. Voir à ce sujet, Evelina Hoisel, Supercaos : os estilhaços da cultura em «PanAmérica e « Nações Unidas », Rio de Janeiro, Civilização Brasileira ; Salvador, Fundação Cultural do Estado da Bahia, 1980.

18. Mautner est surtout connu comme compositeur. Selon Caetano Veloso, Glauber Rocha aurait dit à Mautner, qu'il avait repris exprès, pour son film Deus e o diabo na terra do sol (1964), les échos du titre de ce texte précurseur. Voir à ce sujet, Caetano Veloso, op. cit., p. 442.

19. Les frères Augusto de Campos et Haroldo de Campos, et le poète Décio Pignatari sont les principaux représentants du mouvement de la poésie concrète.

20. Essais réunis dans Augusto de Campos, Balanço da bossa e outras bossas, São Paulo, Perspectiva, 1974.

21. Caetano Veloso, op.cit., p. 19.

22. Cité par José Carlos Teixeira, Revista da Bahia, op. cit. p. 27.

23. Glauber Rocha, "Romance de José Lins do Rego ", Mapa, n² 2, Salvador, ABES, 1957, essai reproduit dans le livre de João Carlos T. Gomes, Glauber Rocha, esse vulcão, Rio de Janeiro, Nova Fronteira, 1997, p. 556-587.

24. Voir, Caetano Veloso, op.cit., p. 99.

25. Glauber Rocha, Revolução do Cinema Novo, Rio, Alhambra / Embrafilme, 1981, p. 138, cité par João Carlos T. Gomes, op. cit. p. 404-405. Cette déclaration est à rapprocher de celle de Caetano Veloso citée dans ce travail : «Tratando-se de arte é sempre perigoso fugir à perspectiva estética ».

26. Glauber Rocha, «Teoria e prática do cinema latino-americano », 1967, cité par João Carlos Teixeira Gomes, op. cit. p. 363.

27. José Carlos Capinan, «Tropicalismo eppur si mueve », Revista da Bahia, op. cit., p. 56.

28. Glauber Rocha, cité par João Carlos T. Gomes, op. cit. p. 245.

29. Ibid., p. 443.

30. Ibid., p. 444.

31. José Carlos Capinan, op. cit., p. 47.

32. Caetano Veloso et Gilberto Gil, « Cinema Novo », Tropicália II, 1997.

33. Voir à ce sujet, Antônio Risério, Avant-garde na Bahia, São Paulo, Instituto Lina Bo e P. M. Bardi, 1995 (Pontos sobre o Brasil).

34. Les trois numéros de Mapa sortirent entre 57 et 58 . La revue Ângulos qui lui succéda incorpora de nouveaux collaborateurs comme Caetano Velloso et João Ubaldo Ribeiro. Je vous renvoie à la lecture de la biographie de Glauber Rocha, écrite par un de ses anciens amis, João Carlos Teixeira Gomes, écrivain et critique lui aussi issu de la « Geração Mapa », qui nous apporte des renseignements précieux, y compris en ce qui concerne le contexte culturel de Bahia à cette période. João Carlos Teixeira Gomes, Glauber Rocha, esse vulcão, Rio de Janeiro, Nova Fronteira, 1997.

35. Sur ce poète et sur les échos du Modernisme dans les années 20 à Bahia, je vous renvoie au livre que j'ai organisé sur le sujet, A poesia de Eurico Alves. Imagens da cidade e do sertão. Salvador, EGBA / Secretaria da Cultura, Coleção Selo Editorial Letras da Bahia, 1999.

36. Dans ce contexte, il faut souligner l'importance fondamentale du travail des musiciens et professeurs Koellreutter et Ernest Widmer. Grâce à eux, Bahia est devenue un centre d'avantgarde de la musique érudite, sans tourner les dos aux sources d'inspiration populaires. 


\section{RÉSUMÉS}

L'article analyse la trajectoire du mouvement Tropicaliste, tendance esthétique qui naît à la fin des années 60 au Brésil. Il s'agira d'examiner sa force créatrice en mettant en relief le processus d'assimilation critique des éléments provenant de sources culturelles diverses. Dans la culture brésilienne, c'est le seul mouvement artistique qui, ayant fait le choix d'allier une réflexion sur la réalité du pays à la sophistication constructive du langage, ait en même temps réussi à avoir un énorme succès populaire. On s'attachera à étudier, plus particulièrement, l'expression musicale du Tropicalisme et son inscription dans la lignée des avant-gardes expérimentales brésiliennes qui l'ont précédé. Tout en gardant des points communs avec le Modernisme et la Poésie Concrète et des affinités avec le Cinéma Nouveau, le mouvement tropicaliste présente évidemment des caractéristiques très particulières que ce travail a l'intention de préciser.

This work investigates the trajectory of the Tropicalist movement, an aesthetic current which is born at the end of the sixties in Brazil. Its creative force is examined by emphasizing the process of critical assimilation of elements originating from different cultural sources.

In Brazilian culture, Tropicalism is the only artistic movement which, having chosen to combine a reflection on the reality of the country and a sophisticated language, has simultaneously succeeded in getting an enormous popular audience.

The musical expression of the Tropicalist movement will be particularly considered in relation with its inscription within the continuity of previous experimental vanguards.

While keeping some similarities with Modernism and Concrete Poetry movements, and affinities with the Cinema Novo, the Tropicalist movement is obviously characterized by peculiarities that will be discussed in this work.

\section{INDEX}

Mots-clés : musique, modernisme, cinéma nouveau, culture populaire

Keywords : music, Modernism, Cinema Novo, popular culture

Index géographique : Brésil

\section{AUTEUR}

\section{RITA OLIVIERI-GODET}

Professeur des Universités, PRIPLAP/ERIMIT - Université de Rennes 2 